\title{
EDITORIALS
}

\section{After the End of Free Fall: Geriatricizing Primary Care}

\author{
Christopher M. Callahan, MD $D^{1,2,3}$ and Malaz A. Boustani, MD, MPH $H^{1,2,3}$ \\ ${ }^{1}$ Indiana University Center for Aging Research, Indianapolis, IN, USA; ${ }^{2}$ Division of General Internal Medicine and Geriatrics, Department of \\ Medicine, Indiana University School of Medicine, Indianapolis, IN, USA; ${ }^{3}$ Regenstrief Institute, Inc., Indianapolis, IN, USA.
}

J Gen Intern Med 23(12):2142-3

DOI: $10.1007 / \mathrm{s} 11606-008-0847-y$

(C) Society of General Internal Medicine 2008

$\mathrm{B}$ y 1965, the baby boomers were already on the planet. It was fairly simple arithmetic to estimate that America would therefore have 65 million older adults about 65 years later. This simple arithmetic, however, was not sufficiently intimidating to stimulate an early investment in "geriatricizing" our health care system. In 1965, Sir Geoffrey Vickers told the story of a man who fell from the top of a skyscraper, "He was heard to say to himself as he whistled past the second floor, 'Well, I'm alright so far'." Vickers suggested that the story captures two absurdities about human behavior. First "is the absurd speed with which we come to accept as normal almost any outrageous condition" and second "is the absurd slowness with which we come to accept as real any impending change which has not yet happened, however near and certain it may be." ${ }^{1}$ We have now reached the end of free fall.

It is no longer the burden of demographers and geriatricians to warn societies about the impending age wave. It is no longer necessary for our researchers and clinicians to document the limitations of our health and social systems relative to the complex care needs of older adults. Any family that has not already had a loved one hit the pavement will soon face this certainty. Even for those of us lucky enough to know something about the vagaries of the medical care system, navigating an older family member through the maze is a daunting task. Over the next few years, we will have more and more video streamed into our living rooms showing deplorable living conditions, incompetent medical care, inadequate nursing care, fraudulent home care, or a complete lack of care for some unfortunate older American who lives somewhere in our town. Vickers, a student of the history of governance and planning, suggested that "the history of public health might well be written as a record of successive redefinings of the unacceptable." ${ }^{1}$ The care of vulnerable older adults has not yet achieved the "unacceptable" definition and we must therefore move forward without a systematic public health response.

So what happens after the end of free fall? Given that it is already too late to prepare a health care system to provide excellent care to older adults, we will have to rely instead on making small improvements in the thousands of small, overburdened, primary care practices across the country. In this issue of JGIM, Ganz et al. take some early steps at outlining a

Published online October 31, 2008 grass-roots approach that is adaptable and adoptable at the practice level. ${ }^{2}$ The authors first highlight the key geriatric principles of communication, personal care plans, and care coordination. These principles are absolutely fundamental to the grass-roots approach because this approach moves decisively towards collaboration between provider and patient and away from "doctor, guidelines, or third-party payor knows best." As clearly stated by Ganz et al.: "there are no absolutes with respect to whether screening, diagnosis, or treatment must occur." This approach also moves the primary care provider into closer collaboration with community services and the local community in general. Indeed, it will likely be the resources of the family and local community that not only deliver the hands-on care for vulnerable elders but that also provide the financial, human, and moral resources needed to sustain this model of primary care for older adults. The place for local communities to look for help in caring for older adults is in primary care and the place for primary care to look for help is in local communities.

Within the general framework of geriatric principles summarized above, Ganz et al. also describe the potential of two delivery models that take into account the inadequate time and resources of the primary care physician and the inadequate number and distribution of providers with geriatrics expertise and resources. Similar to the goals of care for older adults, there are no absolutes about which model is best for which primary care practice or which patients. The availability of local resources will define what is possible. There are also multiple hybrid models available that utilize features of both co-management and augmented primary care. The encouraging news is that these models can deliver better care and better outcomes for vulnerable older adults. ${ }^{3}$ The discouraging news is that they require access to geriatrics expertise and communications infrastructure that is not available in the modal primary care practice in the United States.

Similar to practice models accepted for end-stage renal disease and cancer, for example, there may be some older adults whose care goals simply cannot be met by primary care and the local community. Even recognizing the foundational role of primary care in providing the majority of care for most elders, some older adults need a majority role for secondary and tertiary care providers. Later stages of Alzheimer's disease and related dimentias may represent such a patient population and there are likely others. Thus, we may need to develop a stronger network of regional referral centers for such patient populations that recognize that these resources simply cannot be provided in every community. Although Ganz et al. summarized the key principles, care models, and tools to "geriatricize" primary care, the authors overlook another crucial 
deficiency: primary care providers need a new paradigm to implement organizational change. Over the past decade, a new science has been born that is investigating new theories and methods to select a change, implement it, and to evaluate its impact in a complex health care system. ${ }^{4-6}$ This new approach views primary care clinics as examples of complex adaptive systems. These practices are composed of a network of semiautonomous individuals who interact with each other and with their surrounding environment in a nonlinear dynamic way. Their dynamic interactions seek to increase the probability of surviving the various external and internal sources of stress and change they face. ${ }^{4-6}$ These stresses could be a new acute or chronic illness facing their established patients; a new Medicare regulation; an exciting research discovery, or a new financial resource constraints. Complex adaptive systems are characterized by emergent behaviors as opposed to predetermined rules and self-organized controls as opposed to hierarchical, pyramid-based, or central controls. ${ }^{5-7}$ Understanding primary care practices as complex adaptive systems enhances our capacity to "geriatricize" primary care and to introduce locally acceptable and effective changes that meet the needs of current and future older Americans. This approach is also consistent with a team approach to care.

We are using the lens of complex adaptive systems to build a co-management model to meet the challenges of caring for the "aging brain" (dementia, delirium, and depression). The "Healthy Aging Brain Center" emerged from discussions with various stakeholders representing primary care, neurology, psychiatry, neuropsychology, geriatrics, and the local community. These stakeholders identified the minimum specifications needed to implement the model but they do not issue mandates or regulations. The center is not a primary, secondary or tertiary care delivery model. The center is a model that recognizes the strengths and weaknesses of primary, secondary, and tertiary expertise and resources and attempts to build a communication and cultural infrastructure that weaves the three care sectors together for the benefit of the patients and their family caregivers. Under current third-party payment schemes, this hybrid model requires substantive upfront investment from the health care system and multiple other stakeholders. We need to move beyond the mythical notion that these approaches are going to save money. Dialysis and chemotherapy cost money to improve quality of life and so does care for the aging brain and other geriatric syndromes.
In the concrete and practical recommendations forwarded in "Key Elements of High-Quality Primary Care for Vulnerable Elders," there is one role for primary care providers left unstated. It should be stated, because after the end of free fall, this role is going to grow as fast as the older adult population grows. In a lecture at the Annual Meeting of the Society of General Internal Medicine in 1998, Julian Tudor Hart discussed the management of expectations of health care. ${ }^{7}$ Patient expectations can be promoted, lowered, or shared and this can be done appropriately or inappropriately and ethically or unethically. Dr. Hart suggests that providers can modulate the volume, cost, and content of medical services through their role in managing patient expectations. After the end of free fall and especially among vulnerable elders, we will all find ourselves lowering expectations for excellent care. This will often be acceptable, appropriate, and ethical, and yet we will all know it could have been different.

Corresponding Author: Christopher M. Callahan, MD; Indiana University Center for Aging Research, 410 West 10th Street, Suite 2000, Indianapolis, IN 46202-3012, USA (e-mail: ccallaha@iupui. $e d u)$.

\section{REFERENCES}

1. Open Systems Group. The Vickers Papers. London: Harper and Row Publishers; 1984.

2. Ganz DA, Fung CH, Sinsky CA, Wu S, Reuben DB. Key elements of highquality primary care for vulnerable elders. J Gen Intern Med. 2008; xxxxx.

3. Institute of Medicine (IOM). Retooling for an Aging America. Washington, DC: The National Academies Press; 2008.

4. McDaniel RR Jr., Jordan ME, Fleeman BF. Surprise, Surprise, Surprise! A complexity science view of the unexpected. Health Care Manage Rev. 2003;28(3)266-78.

5. Boustani M, Schubert C, Sennour Y. The Challenge of Supporting Care for Dementia in Primary Care. Clinical Intervention in Aging. 2007;2:631-6.

6. Stroebel CK, McDaniel RR Jr., Crabtree BF, Miller WL, Nutting PA, Stange KC. How complexity science can inform a reflective process for improvement in primary care practices. Jt Comm J Qual Patient Saf. 2005;31(8)438-46.

7. Hart JT. Expectations of health care: promoted, managed, or shared? Health Expectations. 1998;1:3-13. 